\title{
Trapping and shooting of Corncrakes Crex crex on the Mediterranean coast of Egypt
}

\author{
S. M. BAHA EL DIN, W. SALAMA, A. GRIEVE and R. E. GREEN
}

\section{Summary}

Fieldworkers counted traps, guns and nets used for bird trapping in sample sections of a $1 \mathrm{~km}$ wide strip of land adjacent to the shore on the Mediterranean coast of Egypt in the autumn of 1994. These data were used to estimate the number of traps, guns and nets in use in the whole $1 \mathrm{~km}$ coastal strip. Information obtained by interviewing bird trappers was used to estimate the number of Corncrakes taken per trap, net and gun in the 1993 and 1994 seasons and from this the total number taken was about 9,000 and 14,000 respectively. Trapping methods and intensity varied with locality but the taking of Corncrakes was widespread. It was estimated that about 9,000 people were involved in trapping and shooting in the coastal strip. The average proportion of the European Corncrake population taken per year on the coast was estimated to be in the range 0.5$2.7 \%$, though this range would be lower if, as seems probable, Corncrakes from Asia are among those passing through Egypt. Further surveys are required to estimate the numbers of Corncrakes taken further inland.

\section{Introduction}

Recent reviews of population trends of the Corncrake Crex crex (L.) (Collar et al. 1994, Tucker and Heath 1994) indicate that the species is declining rapidly in most of its world range. As a result it is listed as being threatened with global extinction (Collar et al. 1994, Groombridge 1994) and is thus of high priority for conservation action.

The Corncrake is a summer visitor to northern Eurasia and winters in south-east Africa (Stowe and Becker 1992). Hence there is a large geographical area within which the causes of its decline might be found. In the breeding season Corncrakes are strongly associated with agricultural grassland managed for the production of hay (Cramp and Simmons 1980). There is considerable evidence indicating that changes in agricultural practice, in particular mechanization of mowing for hay and silage, are the principal causes of the decline, at least in western Europe (Norris 1947, Green and Stowe 1993, Stowe et al. 1993). Factors operating outside the breeding season were reviewed as possible causes of population decline by Stowe and Becker (1992). They did not find compelling evidence of factors likely to be causing declines. However, largely as a result of unpublished studies by W.C. Mullie, they singled out the by-catch of Corncrakes associated with the autumn trapping of Quail Coturnix coturnix and other bird species in northern Egypt as being of concern. Pilot studies were then carried out to assess the feasibility of making more precise 


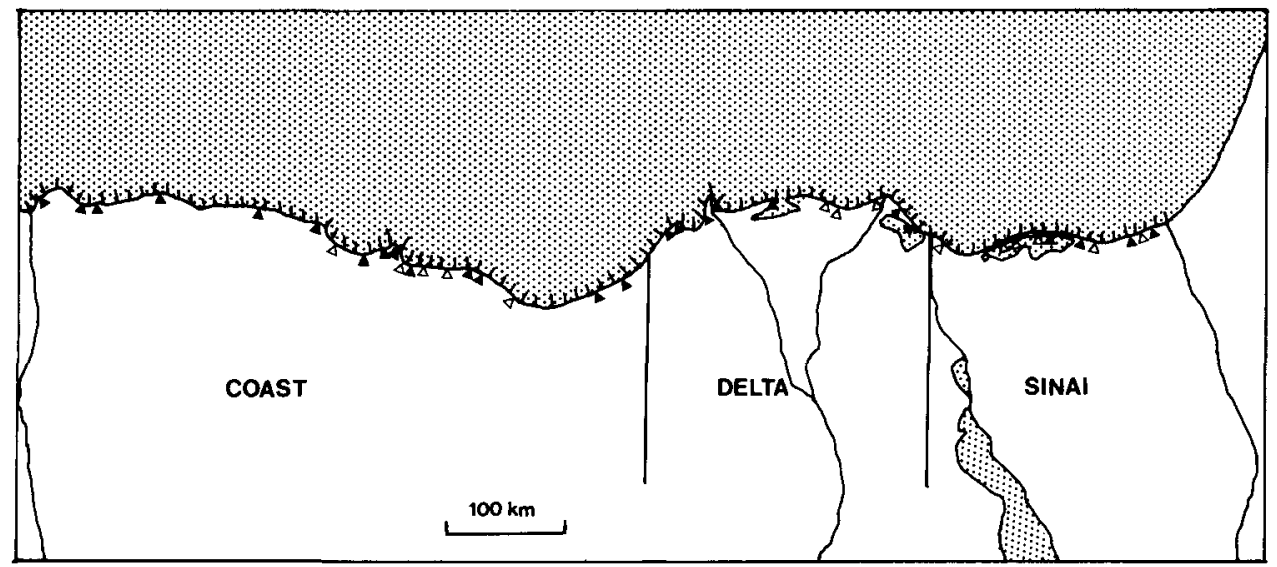

Figure 1. Map of the Mediterranean coast of Egypt divided into $10310 \mathrm{~km}$ sections. Surveys of Corncrake trapping were carried in the sections marked with triangles. Filled triangles show sections in which interviews with trappers were also carried out. Also shown are the three major divisions of the coast, Sinai (sections 1-21, numbering from east to west), Delta (sections 22-50) and Coast (sections 51-103).

estimates of the number of Corncrakes trapped per year on the north coast of Egypt (Baha el Din 1991, Baha el Din and Salama 1991). This work led to a survey in 1994 which is the subject of this paper.

\section{Description of trapping methods}

A wide range of bird-trapping methods was encountered during the survey, including guns (shotguns and air rifles), nets and several types of traps. Trammel nets are flight nets consisting of vertical walls of netting set parallel to the shore to take birds in flight as they reach land. They are set mainly to catch Quail. Eb nets are small nets usually set to cover shrubby vegetation placed artificially by hunters to attract birds in sparsely vegetated areas. Birds resting in or under the vegetation are flushed into the closed side of the net by the trapper. Haleg traps and the similar mansab are large to medium sized nets set over vegetation. Birds are flushed into their closed ends. The toraha is a circular or fan-shaped throw-net, weighted at the edges, which is cast by hand over vegetation. Birds fly or run into the net and are entangled. The romaka is a net which is dragged over vegetation, usually by two people. Birds are disturbed and fly upwards into the net as it passes over them. The net is then dropped to trap them. Further details of trapping methods are provided by Baha el Din and Salama (1991).

\section{Sample selection}

The objective of the survey was to estimate the number of Corncrakes taken by humans in a $1 \mathrm{~km}$ wide strip of land adjacent to the sea along the whole Mediterranean coast of Egypt (Figure 1). Bird trapping is believed to be 
Table 1. Numbers of $10 \mathrm{~km}$ sections of the Mediterranean coast of Egypt included in the survey of Corncrake-trapping in autumn 1994

\begin{tabular}{lrccccc}
\hline & \multicolumn{5}{c}{ Number of sections } & \\
\cline { 2 - 5 } Division & Total & Selected & Surveyed & With questionnaires & Number of questionnaires \\
\hline Coast & 53 & 19 & 19 & 14 & 184 \\
Delta & 29 & 10 & 6 & $4^{\mathrm{a}}$ & $8^{\mathrm{a}}$ \\
Sinai & 21 & 10 & 9 & $4^{\mathrm{b}}$ & $53^{\mathrm{b}}$ \\
Entire coast & 103 & 39 & 34 & 22 & 285 \\
\hline
\end{tabular}

${ }^{a}$ Includes one section in which seven questionnaires were completed by accident.

${ }^{b}$ Includes one section in which one questionnaire was completed by accident.

concentrated in this strip. However, the activity is also known to occur further inland, so the present survey only covers part of the area in which trapping occurs. The strip was divided into 103 sections corresponding to divisions of $10 \mathrm{~km}$ on a $1: 950$, 000 map. Thirty-nine of these were selected at random for counting of traps, guns and nets. It was not possible to survey five of these sections because of lack of time or restrictions on access. The $10 \mathrm{~km}$ sections were grouped into three regions for the purposes of analysis (Figure 1), but the selection of sample did not involve prior stratification by region.

From the 39 survey sections 25 were selected at random for questionnaire surveys involving interviews with trappers. The survey was carried out in 22 of the selected sections but no trappers were located in two of these. In addition, one questionnaire was completed in error for a section adjacent to one selected and covered by the survey and seven questionnaires were completed in error for another section which was not in the random sample. Details of the sections selected and actually covered by the survey are given in Table 1 and Figure 1 .

\section{Data collection}

Fieldwork was carried out between 6 September and 11 October 1994. For logistical reasons it was not possible to survey the sections in random order. As a result, adjacent sections tended to be surveyed within a few days of each other. Surveys in Sinai were later than those in the other two regions.

Each $10 \mathrm{~km}$ section was viewed by driving along roads and tracks. The numbers of traps, guns and metres of net present in the $1 \mathrm{~km}$ wide coastal strip were estimated in every $1 \mathrm{~km}$ subsection. Most haleg and eb traps and trammel nets were left in place continuously during the trapping season, so the time of day and day of the week probably had little influence on the numbers recorded. However, the number of guns, romakas and torahas varied with the time of the visit so efforts were made to estimate the approximate average numbers of these by discussion with trappers encountered during the survey.

In sections selected for the questionnaire survey, a trapper or group of trappers was approached and asked to participate. Very few refused. Respondents were first shown pictures of Corncrake and Quail to make sure that there was no possibility of confusion between the two species. The information listed in Table 2 was elicited by informal questioning. 
Table 2. Information collected in $10 \mathrm{~km}$ sections selected for the survey

\begin{tabular}{lc}
\hline & Symbol $^{\mathrm{a}}$ \\
\hline Section survey form (one per 1o km section) & $k_{1}$ \\
Date of survey & $k_{2}$ \\
Metres of trammel net & $k_{3}$ \\
Metres of mist net & $k_{4}$ \\
Number of haleg traps & $k_{5}$ \\
Number of eb traps & $k_{6}$ \\
Number of toraha traps & $k_{7}$ \\
Number of romakas & $k_{8}$ \\
Number of airguns & \\
Number of shotguns & \\
Questionnaire (one per group of trappers) & $t_{v}$ \\
Trap type & $t_{\mathrm{b}}$ \\
Occupation of interviewee & $t_{\mathrm{e}}$ \\
Date of survey & $n$ \\
Date of beginning of hunting season & $m$ \\
Date of end of hunting season & $\mathrm{c}_{\mathrm{r}}$ \\
Number of traps or length of net operated by the group & $c_{\mathrm{p}}$ \\
Number of trappers associated with these traps & $c_{93}$ \\
Number of Corncrakes trapped in the past week & \\
Number of Corncrakes trapped so far in 1994 &
\end{tabular}

a Symbols are used in statistical analyses.

\section{Statistical analysis}

It was decided to proceed with the analysis as if the sample had been perfectly random, in spite of the omissions and erroneous additions to the dataset described above. It was thought to be unlikely that the omitted or erroneously included data would differ markedly from sampled sections within the same region. However, as most of the omitted sections were in the Delta region, it was considered important to make region-specific estimates. Symbols representing quantities measured by the survey are given in Table 2.

Estimates of the total number of traps, guns and metres of trammel and mist nets were obtained for each of the three regions by extrapolating the numbers found in the sample sections to the whole coast. For example, the number of metres of trammel nets in the Sinai region $K_{1 \mathrm{~s}}$ was given by

$$
K_{1 \mathrm{~s}}=21 \sum k_{1} / 9
$$

i.e. the lengths of net in the 9 sampled sections $\left(k_{1}\right)$ were summed and divided by the sampling fraction $(9 / 21)$.

The rate at which Corncrakes were trapped on a given day of the autumn, given that trappers were operating their nets or traps was assumed to vary with time through the season in direct proportion to the probability density of a normal distribution with mean $d$ and standard deviation $s$. It was assumed that $d$ and $s$ could be taken as the same for all parts of the Mediterranean coast of Egypt. By making these assumptions it was possible to estimate $d$ and $s$ from changes through the season in the numbers of Corncrakes caught by each trapper in the week prior to the interview relative to the numbers he trapped 
in the whole season up to the date of the interview. For a given trapper, the expected number of Corncrakes caught in the week prior to the interview is given by

$$
E\left(c_{\mathrm{r}}\right)=c_{\mathrm{p}} N\left(d, s, t_{\mathrm{v}-7}, t_{\mathrm{v}}\right) / N\left(d, s, t_{\mathrm{b}}, t_{\mathrm{v}}\right)
$$

where $N\left(d, s, t_{1}, t_{2}\right)$ is the normal integral between dates $t_{1}$ and $t_{2}$, given mean $d$ and standard deviation $s$. Estimates of $d$ and $s$ were obtained by assuming the observed values of $c_{\mathrm{r}}$ to be a Poisson variable with expected mean $E\left(c_{\mathrm{r}}\right)$ and maximizing the logarithm of the relative likelihood,

$$
\sum c_{\mathrm{r}} \log _{\mathrm{e}}\left(E\left(c_{\mathrm{r}}\right)\right)-E\left(c_{\mathrm{r}}\right)
$$

where summation is over all trapper questionnaires. The simplex search routine within the NONLIN module of SYSTAT 5.0 (Wilkinson 1990) was used to make the estimates. Ideally $d$ and $s$ would have been estimated separately for each region and trap type, but there were insufficient data for this.

Having estimated $d$ and $s$, the numbers of Corncrakes likely to be caught in the entire 1994 season by each trapper, $C$, was estimated by

$$
C=c_{\mathrm{p}} N\left(d, s, t_{\mathrm{b}}, t_{\mathrm{e}}\right) / N\left(d, s, t_{\mathrm{b}}, t_{\mathrm{v}}\right)
$$

Mean rates $R_{\mathrm{ij}}$ of taking of Corncrakes over the entire 1994 season, per trap, gun or metre of net were obtained for the $i$ th trap type and $j$ th region as

$$
R_{\mathrm{ij}}=\sum C_{\mathrm{i}} / \sum n_{\mathrm{i}}
$$

where the $C$ and $n$ were summed for all questionnaires for trap type $i$ within the jth region. These rates were then multiplied by the estimated number of traps, guns or metres of net of that type present in that region to give the estimated total number of Corncrakes taken by that method in that region in 1994. In a few cases a trap type was recorded as being occasionally used within a region on the section surveys but was sufficiently rare that no questionnaires were obtained for that region from trappers using it. In these cases the average rate of capture of Corncrakes per trap of that type for the whole coast was used.

Numbers of Corncrakes taken in 1993 were estimated by calculating the ratio

$$
\sum c_{93} / \sum C
$$

for each trap type and region, excluding a few questionnaires in which Corncrake capture data were not supplied for both 1993 and 1994. The estimated take of Corncrakes in 1994 for each trap type and region was then multiplied by this ratio to give an estimate of the 1993 take. This method assumes that the same trappers were involved in both years.

The number of people involved in trapping with the $i$ th trap type in the $j$ th region was calculated as;

$$
K_{\mathrm{ij}} \sum m_{\mathrm{i}} / \sum n_{\mathrm{i}}
$$

where the $m_{\mathrm{i}}$ and $n_{\mathrm{i}}$ were summed for all questionnaires concerning the $i$ th trap type in the $j$ th region. In the few cases in which a group of trappers was using two trap types half of the number of operators was attributed to each trap type.

The $95 \%$ confidence limits $(95 \% \mathrm{CL}$ ) for the Corncrake capture totals and the parameters of the normal distribution of capture rate were obtained by a 
bootstrap method (Efron 1979). Within each region, bootstrap samples of sections were taken which contained the same number of sections with net, trap and gun surveys and trapper questionnaires as were collected in the original sample. All questionnaires for a section selected by the resampling procedure were included. For the purpose of this procedure, the single questionnaire collected in error in section 12 was attributed to section 11 . The parameters of the normal distribution, $d$ and $s$, were estimated from the bootstrap sample of questionnaires and used to obtain the $R_{\mathrm{ij}}$ (see above). Numbers of Corncrakes taken in the original section survey samples were then calculated from the $R_{\mathrm{ij}}$ and the numbers of traps, guns and metres of net observed in those sections. The number of Corncrakes taken outwith the original sample sections was calculated from the $R_{\mathrm{ij}}$ and the bootstrap estimates of the numbers traps, guns and metres of net in the unsampled sections. The Corncrake estimates for the original sample sections and the unsampled sections were then added together. Confidence intervals were taken to be the limits containing the central 950 of 1,000 bootstrap estimates as described by Manly (1991).

\section{Results}

\section{Seasonal variation in trapping rate}

The number of Corncrakes reported to have been taken in the 7 days preceding the questionnaire interview, as a proportion of the total taken in the season up to the interview, was higher for interviews early than late in the study period. This variation provided the basis for the estimation of the mean and standard deviation of the Corncrake-trapping rate. The estimated mean, corresponding to the date with the peak trapping rate, was 22 September $(95 \%$ CL $19-25$ September) and the standard deviation of the distribution describing trapping rate variation through the season was 9.4 days (95\% CL 5.4-13.3 days). If trapping rate was mainly determined by the density of migrant Corncrakes, this would be equivalent to $95 \%$ of the Corncrake migration occurring between 4 September and 10 October. The downward trend with date in the proportion of Corncrakes caught in the week before the interview would be expected from a wide range of patterns of temporal variation in trapping rate, but the observed form of the relationship was in accord with that expected from the fitted normal distribution (Figure 2). A simpler model in which trapping rate was uniform from 1 September, at least until after the date of the last interview, gave a much poorer fit than for the normal model (Figure 2).

\section{Numbers of traps, guns and nets}

The prevalence of the trapping methods varied considerably among regions (Table 3). Haleg traps, romakas, mist nets and guns were mainly found in the western Coast region while trammel nets and torahas were the predominant trapping methods in Sinai and the Delta. Eb nets were found in large numbers in the Coast and Delta regions. The intensity of trapping effort is especially striking in Sinai, where trammel nets are set in lines parallel to the coast. It is 


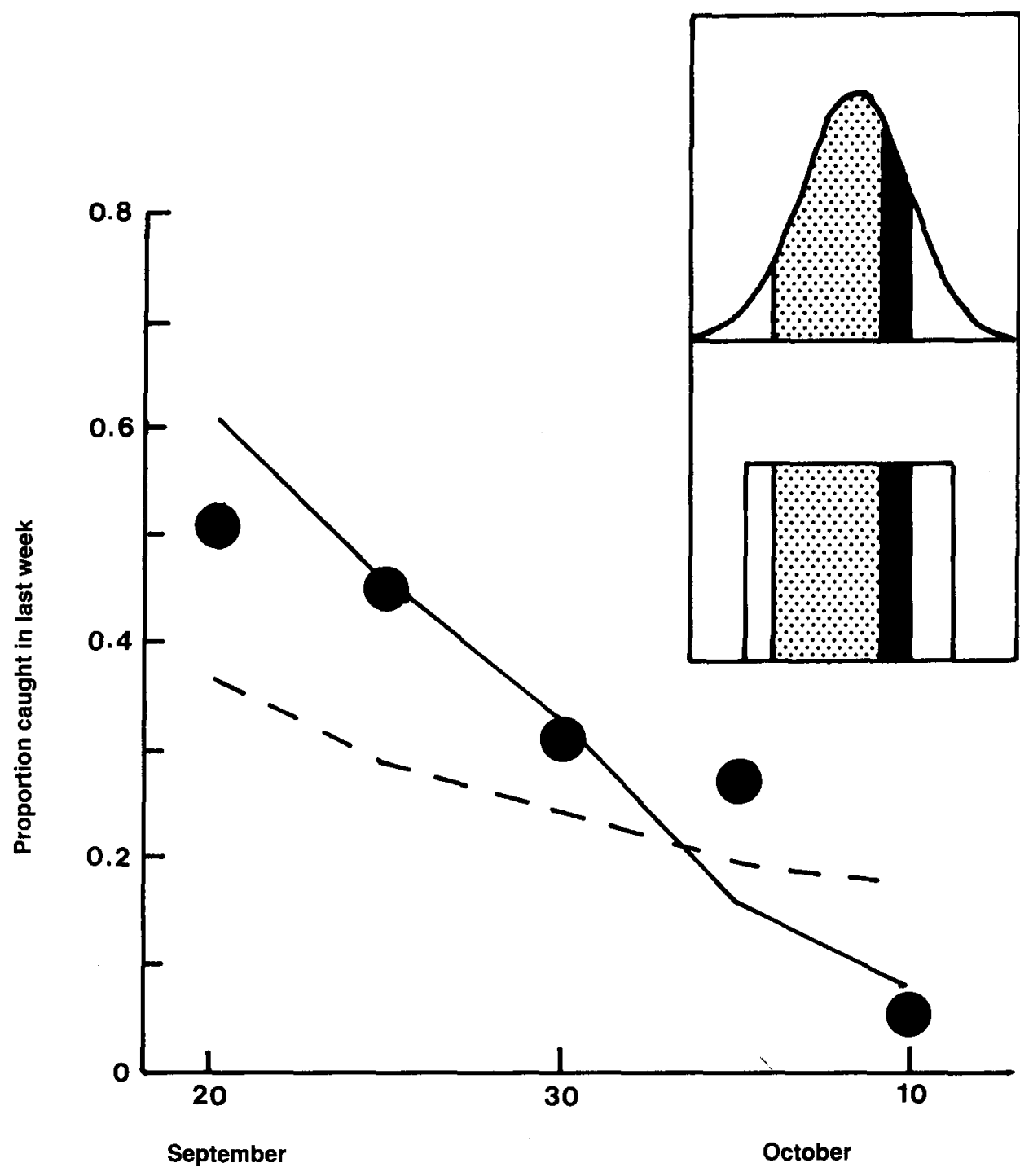

\section{Date of interview}

Figure 2. Estimation of the time of passage of Corncrakes through the study area from interviews with trappers. The curves in the small inset diagrams describe hypothetical changes in the abundance of Corncrakes in relation to date. The solid and shaded areas are equivalent to the expected number of birds taken in the week prior to the interview (solid) and the number taken from the beginning of trapping to the date of the interview (shaded and solid combined). The upper inset shows a normal distribution of Corncrake incidence and the lower inset a uniform distribution between the dates of onset and cessation of passage. The main diagram shows (dots) the number of Corncrakes trapped in the week before the interview as a proportion of the total number taken before the interview, for various ranges of interview date. The solid line shows the result expected if the rate of trapping varied with date according to the fitted normal distribution with the mean of 22 September and standard deviation of 9.4 days. In the inset this is equivalent to plotting the ratio of the solid shaded area to the total shaded and solid shading against interview date. The broken line shows the result expected if the rate of trapping was uniform from 1 September onwards. 


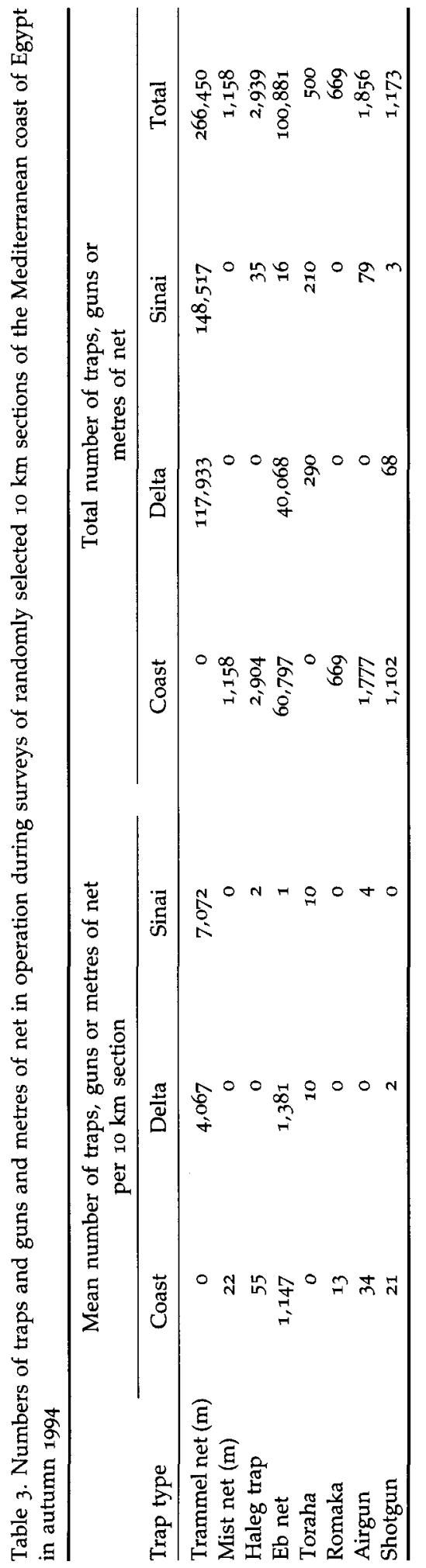


estimated that $71 \%$ of the Sinai coast had a trammel net within $1 \mathrm{~km}$ of the shore (Table 3).

\section{Numbers of Corncrakes taken in 1994}

Respondents to the questionnaire survey said that they had taken 767 Corncrakes up to the date of interview in 1994. Allowing for additional birds caught in the remaining part of the season and applying the estimated numbers taken per trap, gun or metre of net to the estimated totals of traps, guns and nets in Table 3 gives a total take in 1994 of about 14,0oo birds (Table 4). Of the total $48 \%$ was estimated to be taken in the western Coast region, $16 \%$ in the Delta and $36 \%$ in Sinai. The mean number of Corncrakes taken per kilometre of coast in the whole season was 24.0 birds $\mathrm{km}^{-1}$ in Sinai, 12.6 birds $\mathrm{km}^{-1}$ on the western Coast and 7.4 birds $\mathrm{km}^{-1}$ in the Delta region.

\section{Numbers of Corncrakes taken in 1993}

Questionnaire respondents reported having taken 487 Corncrakes in 1993 and the estimate of the total taken in that year, based on the ratio of numbers taken in the two years, was about 9,000 (Table 3). Trappers indicated in conversation that Corncrakes were being caught in unusually high numbers in 1994. There was an east to west trend in the difference between the two years; the ratio of the 1994 to 1993 take being 3.7 in Sinai, 2.0 in the Delta and 1.1 in the Coast region.

\section{People involved in bird trapping}

It was estimated that about 9,000 people were involved in bird trapping in the coastal strip (Table 5). It is difficult to estimate the proportion of these involved in trapping Corncrakes because the mean number taken per trapper was low, so some of the trappers who did not report having taken the species might simply not have had the opportunity to do so in the years of the study. Corncrakes are mainly taken incidentally in catching and shooting Quail and passerines and can be taken by a wide range of methods. Therefore it is likely that most people involved in bird trapping and shooting take Corncrakes, though they might not catch any in some years.

The majority of those involved in bird trapping and shooting worked in farming $(56 \%)$, with schoolchildren/students and fishermen as the next most important groups. Only $4 \%$ indicated that hunting or trapping was their main occupation.

\section{Discussion}

Accuracy of the survey

Several of the assumptions made in deriving the estimates of the numbers of Corncrakes taken could, if incorrect, lead to errors. It was assumed that variation in trapping rate with time of year followed a normal distribution. If 


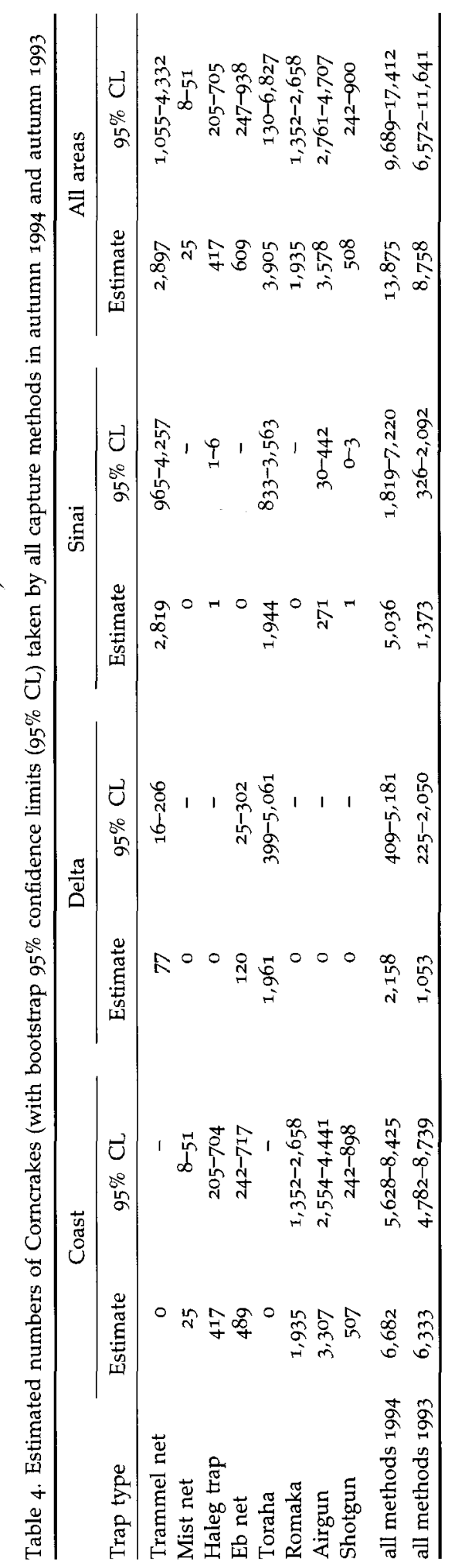


Table 5. Estimated numbers of trappers by trap type and occupation

\begin{tabular}{|c|c|c|c|c|}
\hline & \multicolumn{4}{|c|}{ Number of trappers } \\
\hline & Coast & Delta & Sinai & Total \\
\hline \multicolumn{5}{|l|}{ Trap type } \\
\hline Trammel net & o & 584 & 733 & 1,317 \\
\hline Mist net & 8 & o & o & 8 \\
\hline Haleg trap & 743 & 0 & 35 & $77^{8}$ \\
\hline Eb net & 283 & 401 & 1 & 685 \\
\hline Toraha & o & 444 & 258 & 702 \\
\hline Romaka & 1,235 & o & 0 & 1,235 \\
\hline Airgun & 2,014 & o & 123 & 2,137 \\
\hline Shotgun & 1,763 & 68 & 5 & 1,836 \\
\hline \multicolumn{5}{|l|}{ Occupation } \\
\hline Farming ${ }^{a}$ & 3,776 & $55^{2}$ & 529 & 4,857 \\
\hline Schoolchild \& student $t^{b}$ & 926 & 89 & 272 & 1,287 \\
\hline Hunter & 119 & 82 & 0 & 201 \\
\hline Fisherman & 113 & 616 & 280 & 1,009 \\
\hline Miscellaneous $^{c}$ & 1,112 & 158 & 74 & 1,344 \\
\hline Total & 6,046 & 1,497 & 1,155 & 8,698 \\
\hline
\end{tabular}

${ }^{a}$ Farmer, tractor driver, shepherd and goatherd.

b Includes recent school-leavers.

' Factory worker, labourer, construction worker, office worker, mechanic, gardener, schoolteacher, driver, shopkeeper.

this assumption is incorrect, then the estimate of the number of Corncrakes taken in the period after the survey fieldwork would be in error. The largest errors would occur if the assumption of a normal distribution led to underestimation of the proportion of Corncrake passage which occurs in October, since survey fieldwork was completed when a substantial part of the trapping season still remained. However, the fit of the data to the assumed model was good and there was agreement between our estimates of the timing of Corncrake passage and those of previous workers (Goodman and Meininger 1989, Baha el Din 1991).

It was assumed that a single survey of traps, nets and guns gave a reliable estimate of the number present during the whole trapping season. The most likely error would be that guns and types of trap which are not left in place when the trappers are absent would be underestimated. This is because not all of the trappers using these methods would necessarily be present at any one time and because many of the survey visits were made at times when the number of trappers present was lower than the maximum. It was recognized in advance that numbers of guns and some traps would be likely to vary with time of day and day of the week, so efforts were made to allow for this (see Data Collection) but this would not be expected to overcome this problem completely. Therefore it seems probable that there was some underestimation of numbers of traps and guns, and hence Corncrakes taken, for this reason.

The numbers of Corncrakes reported by trappers as having been taken might have been inaccurate. Efforts were made to ensure that interviewees did not mistakenly report other bird species as Corncrakes. Interviewees gave figures from memory and did not refer to written records. However, the number of 
Corncrakes taken in a season by one trapper is small enough to have been remembered accurately. Trappers may have deliberately misled the fieldworkers about the numbers of Corncrakes taken. However, the fieldworkers are of the opinion that, because of preliminary conversations to put the respondents at their ease and the informal style of the interview, the great majority appeared to answer the questions truthfully.

It was assumed that the rate of taking of Corncrakes per trap, gun or metre of net obtained from the interviews could be taken as representative of that for all the traps, guns and nets in operation. This might not be the case if a biased sample of trappers was interviewed. The most plausible bias would be that trappers who make the most effort to catch birds might be the ones who would be most likely to be encountered and interviewed during a single visit to a section of coast. The capture rates derived from these interviews would also be applied to the traps and nets of less active trappers and this would lead to overestimation of the number of Corncrakes taken. A practical method for avoiding this bias or estimating its likely magnitude has not been devised.

It is concluded that there are possible errors from several sources which might affect our estimates of the numbers of Corncrakes taken, but that the most plausible errors are in opposing directions and would therefore tend to cancel each other out, at least in part.

\section{Comparison with previous work}

The findings reported here confirm previous work which indicated that thousands of Corncrakes were taken each year in Egypt as a by-catch of trapping and shooting directed mainly at Quail and passerines. Mullie (in Stowe and Becker (1992) ) estimated that 225-2,250 Corncrakes were caught annually in the 1980s, but the precision and possible biases in this estimate are uncertain. Baha el Din (1991) estimated that 4,600 Corncrakes were caught in autumn 1991. This is less than half the catches estimated for 1993 and 1994 by the present study. However, the estimates for 1991 were mainly derived from records of the total numbers of Corncrakes taken in a relatively small area, the Corncrake work being only part of a larger project covering the hunting of other species. Five sample lengths of coast totalling $25.5 \mathrm{~km}(2.5 \%$ of the total Mediterranean coast of Egypt) were studied. Numbers of Corncrakes taken per kilometre in the whole season, in the three sample lengths for which this was reported, were quite variable $\left(6.1\right.$ birds $\mathrm{km}^{-1}$ in Coast region and 4.9 and 22.5 birds km $\mathrm{km}^{-1}$ in Sinai, so the difference between the estimates for 1991 and 1993-94 is almost certainly not statistically significant. Furthermore, the sample lengths in the 1991 study were not selected at random, so bias might also have contributed to the apparent difference. Baha el Din (1991) considered that trappers might report more Corncrakes than they actually took and he therefore selected sample sections of coast where he was confident of the accuracy of the reported numbers. The 1993-94 results are based entirely on interviews with trappers and the numbers of birds they reported are taken at face value. Hence the possibility that the difference between the results for 1991 and 1993-94 is attributable to this problem, at least in part, cannot be excluded. 
Many trappers and other local people indicated that the volume of migration in 1994, both of Corncrake and Quail, was considerably larger than for several previous years. Hence a single season in which Corncrakes were unusually numerous on the Egyptian coast may also have contributed to the difference between this and previous estimates.

\section{Conservation measures}

During the autumns of 1993 and 1994 a concerted effort was made to reduce the number of Corncrakes killed on the Mediterranean coast of Egypt. Trappers were encouraged and persuaded to avoid trapping and shooting Corncrakes and to release birds that they caught. After every interview each trapper was presented with a booklet, poster and sticker about Corncrake conservation which indicated the importance of Egypt as a staging area on the birds' long migration route. Most trappers showed interest and understanding and expressed a willingness to cooperate with our requests. The majority promised to release all the Corncrakes they caught in the future. The extent to which these promises have been kept is uncertain but some trappers visited again after the interview claimed to have released or avoided catching Corncrakes in the intervening period.

\section{Impact of the trapping and shooting on Corncrake populations}

The Corncrake is not the main target species of bird trappers and hunters in Egypt and only a handful of the people interviewed claimed to make any efforts to seek them out as quarry. Corncrakes did not survive being transported to markets as well as other species, such as Quail, and were usually retained by trappers for their own use as food. Some of the Corncrakes taken were reported to have been released unharmed but the information collected on this from the questionnaire survey may not have been reliable. In any case, it is probable that a large proportion of the birds taken were sufficiently harmed by capture to make long-term survival after release unlikely. It is probably best to regard the great majority of the Corncrakes taken on the coast of Egypt as having been killed.

The estimated take of Corncrakes within $1 \mathrm{~km}$ of the Mediterranean coast of Egypt is compared with estimates of the size of the European breeding population in Table 6 . The population estimates are based upon the range of the number of singing males given by Tucker and Heath (1994). Studies of survival rates and productivity in Scotland and Ireland lead to an estimate of about seven Corncrakes alive in autumn for each singing male (G. A. Tyler and R. E. Green unpubl. data). Taking various combinations of possible values for the take and the population at risk leads to the conclusion that the proportion of the European Corncrake population taken is in the range 0.5-2.7\% (Table 6). This assumes that no birds are taken in Egypt which come from the breeding populations of Corncrakes in Asia, which may comprise more than half of the world population (Tucker and Heath 1994). The few ringing recoveries of Corncrakes in Egypt are of birds from breeding populations in Sweden and 
Table 6. Comparison of various estimates of the number of Corncrakes taken per autumn in Egypt with estimates of the European population in autumn obtained from the upper and lower limits of the estimated numbers of singing males in Europe given by Tucker and Heath (1994). (See text for further details.)

\begin{tabular}{|c|c|c|c|c|}
\hline \multicolumn{2}{|l|}{ Estimate of take } & \multicolumn{2}{|c|}{ Estimate of autumn stock } & \multirow{2}{*}{$\frac{\text { Take as } \% \text { of stock }}{1.0}$} \\
\hline 1993 lower $95 \%$ limit & 6,572 & $7 \times$ Tucker \& Heath lower limit & 644,000 & \\
\hline & & limit & 1,4 & 0.5 \\
\hline 1993-94 mean & 11,317 & $\begin{array}{l}7 \times \text { Tucker \& Heath lower limit } \\
7 \times \text { Tucker \& Heath upper limit }\end{array}$ & $\begin{array}{r}644,000 \\
1,400,000\end{array}$ & $\begin{array}{l}1.8 \\
0.8\end{array}$ \\
\hline 1994 upper $95 \%$ limit & 17,412 & $\begin{array}{l}7 \times \text { Tucker \& Heath lower limit } \\
7 \times \text { Tucker \& Heath upper limit }\end{array}$ & $\begin{array}{r}644,000 \\
1,400,000\end{array}$ & $\begin{array}{l}2.7 \\
1.2\end{array}$ \\
\hline
\end{tabular}

Finland (Baha el Din 1991), but the review of records by Stowe and Becker (1992) makes it seem probable that Corncrakes from a much larger part of Eurasia pass through Egypt. If Asian Corncrakes pass through Egypt then the proportion of the population at risk which is taken by trapping and shooting is even less than indicated by Table 6. Any tendency for those birds taken to be individuals which are weak and unlikely to survive even if they were not trapped would further reduce the impact of the take on Corncrake populations. It seems unlikely, therefore, that even the complete prevention of any killing of Corncrakes in the coastal strip of Egypt would lead to an increase of more than about $1 \%$ in the chance that a European Corncrake will survive the non-breeding season. However, in view of the uncertainty about the extent of trapping away from the coast and the threatened status of the species, measures to minimize the numbers of birds taken are still considered worthwhile.

\section{Further research}

The scale of taking of Corncrakes in Egypt as a whole might be larger than indicated by this survey. Bird trapping is known to occur inland from the coastal strip. Baha el Din (1991) reported that there was considerable evidence of bird catching within $5 \mathrm{~km}$ of the coast in the North Coast region west of the Nile Delta and some catching was seen up to $38 \mathrm{~km}$ inland. However the number of Corncrakes taken more than $1 \mathrm{~km}$ from the shore is unknown. A further survey is planned to investigate this. Corncrakes may also be taken in substantial numbers elsewhere in North Africa and the Middle East where the practice has not yet been studied in detail. However, even if the total number of birds taken is several times that for the coastal strip, it seems unlikely that the impact on Corncrake populations of trapping on autumn migration approaches that of habitat loss and destruction of eggs and chicks by mechanized mowing of hay and silage in the breeding areas (Green 1995).

\section{Acknowledgements}

We are grateful to the many bird-trappers who contributed to the survey. Gary Allport and Gwyn Williams gave advice during the planning of the study. Mark Avery and Gwyn Williams commented on a draft. 


\section{References}

Baha el Din, S. (1991) The catching of Corncrakes Crex crex and other birds in Northern Egypt. Unpubl. report. Sandy, Bedfordshire, U.K.: Royal Society for the Protection of Birds.

Baha el Din, S. and Salama, W. (1991) The catching of birds in North Sinai, autumn 1990. Cambridge: International Council for Bird Preservation. (ICBP Study Report No. 45).

Collar, N. J., Crosby, M. J. and Stattersfield, A. J. (1994) Birds to watch 2: The world list of threatened birds. Cambridge: BirdLife International. (BirdLife Conservation Series No. 4)

Cramp, S. and Simmons, K. E. L. (1980) Handbook of the birds of Europe, the Middle East and North Africa, vol. II. Oxford: Oxford University Press.

Efron, B. (1979) Bootstrap methods: another look at the jack-knife. Ann. Stat. 7: 1-26.

Green, R. E. (1995) Diagnosing causes of bird population declines. Ibis (Suppl.) 137: S47S55.

Green, R. E. and Stowe, T. J. (1993) The decline of the Corncrake in Britain and Ireland in relation to habitat change. J. Appl. Ecol. 30: 689-695.

Goodman, S. M. and Meininger, P. L. (1989) The birds of Egypt. Oxford: Oxford University Press.

Groombridge, B. (1994) (ed.) 1994 IUCN red list of threatened animals. Cambridge: World Conservation Monitoring Centre.

Manly, B. F. J. (1991) Randomisation and Monte Carlo methods in biology. London: Chapman and Hall.

Norris, C. A. (1947) Report on the distribution and status of the Corncrake. Brit. Birds 40: 226-244.

Stowe, T. J. and Becker, D. (1992) Status and conservation of the Corncrake Crex crex outside the breeding grounds. Tauraco 2: 1-23.

Stowe, T. J., Newton, A. V., Green, R. E. and Mayes, E. (1993) The decline of the Corncrake in Britain and Ireland in relation to habitat. J. Appl. Ecol. 30: 53-62.

Tucker, G. and Heath, M. F. (1994) Birds in Europe: their conservation status. Cambridge: BirdLife International (BirdLife Conservation Series No. 3).

Wilkinson, L. (1990) SYSTAT: the system for statistics. Evanston: SYSTAT Inc.

\section{S. M. BAHA EL DIN}

4 Ismail El Mazni St, Apartment 8, Heliopolis, Cairo, Egypt

W. SALAMA

Post Box 3, El Salam, El Arish, North Sinai, Egypt

A. GRIEVE

R. E. GREEN

Royal Society for the Protection of Birds, 17 Regent Terrace, Edinburgh EH7 5BN, U.K. 